\title{
Analysis of Economic Transformation Capacity and Convergence of Resource-Regenerative Cities-Based on Entropy Weight TOPSIS Method
}

\author{
Guangcheng Ma \\ Business College, Nanjing Normal University, Nanjing, China \\ Email: sherlock_mgc@outlook.com
}

How to cite this paper: Ma, G.C. (2019) Analysis of Economic Transformation Capacity and Convergence of Resource-Regenerative Cities-Based on Entropy Weight TOPSIS Method. American Journal of Industrial and Business Management, 9, 16821698.

https://doi.org/10.4236/ajibm.2019.98110

Received: July 29, 2019

Accepted: August 20, 2019

Published: August 23, 2019

Copyright $\odot 2019$ by author(s) and Scientific Research Publishing Inc. This work is licensed under the Creative Commons Attribution International License (CC BY 4.0).

http://creativecommons.org/licenses/by/4.0/

\begin{abstract}
By constructing an evaluation index system of economic transform capacity of the resource-regenerated cities with 17 indexes, this paper uses the entropy weight TOPSIS method to set index weight and calculates the economic transformation capacity of 11 resource-regenerated cities during 2013 to 2016 in China. Then beta convergence test conducted on the economic transformation capacity of those cities. Results show that about 9 cities have an obvious changes and the ability of economic transforming gap between cities have been narrow. Economic adjustment is a key index that decides economic change. 11 cities economic transformation capacity show they have beta convergence ability, which means that the lag behind economic transformation ability cities have "catch up effect" with developed regions in their developing period. It shows that 11 cities still need to strengthen the economic adjustment, further reduce the gap and improve the ability of the economic transformation.
\end{abstract}

\section{Keywords}

Resource-Regenerated Cities, Economic Transformation Capacity, Evaluation Index System, Entropy Weight TOPSIS Method, Beta Convergence

\section{Introduction}

In November 2013, the State Council promulgated the "National Resource-Based City Sustainable Development Plan (2013-2020)" (hereinafter referred to as "Planning"), which designated 262 cities nationwide as resource-based cities and divided resource-based cities into growth. Four types, namely, mature, declining 
and regenerative, define the development direction and key tasks of each type of city. According to the "China's Urban Competitiveness Report" edited by $\mathrm{Ni}$ Pengfei, resource-based cities are weaker in competitiveness and generally show a downward trend. Therefore, it is necessary to study the path of economic transformation and upgrading of resource-based cities, the influencing factors, and the existing drawbacks. The transformation of economic development mode, the coordinated development of regional coordination and the maintenance of social harmony and stability are of great significance. In the classification of resource-based cities, according to the definition of "Planning", resource-recycling cities are basically rid of the dependence on resources, and the economic society has begun to enter a benign development track. It is the forerunner of resource-based cities to transform economic development. Li Jiangsu (2017) believes that the development of resource-recycling cities and industrial structural changes and their influencing factors have important guiding value for other types of urban transformation [1].

However, research scholars have less discussion on resource-recycling cities, mostly focusing on the discussion of the overall resource-based city. Li and Dewan (2017) resource-based cities have made great contributions to China's economic growth. Resource-based cities are development models based on the development of natural resources and primary processing, so the resource industry is the leading industry of the urban economic system [2]. In addition, in the context of China's rapid industrialization and urbanization, some scholars have explored problems in the development and transformation of resource-based cities. For example, Huijuan Li, Ruyin Long and Hong Chen (2013) found that the development of resource-based cities lags behind. In other cities, this may be due to planned economy, unreasonable taxation, and wrong resource development policies [3]; Li et al. (2017) found that unsustainable development, industrial growth imbalances, and environmental degradation are resource-based cities that are over-reliant on resources and the result of inefficient use of resources [4].

At present, there are three main methods for evaluating the economic transformation ability of a city. The first method is to directly reflect the development of the city by using one or more indicators (Wenqiang Zhang, Fang Zhao and Yetang Wang, 2016), which can highlight one aspect of the city's characteristics and obtain targeted evaluation results [5]. The disadvantage of this method is that it cannot comprehensively evaluate the city level. The second method is to calculate the input and output through mathematical analysis. This data envelopment analysis (DEA) method is widely used to evaluate the development efficiency of cities (Hossein Haghshenas, Manouchehr Vaziri and Ashkan Gholamialam, 2015 [6]; Li and Dewan, 2017 [2]; Xiao Sun, Xusheng Liu, Feng Li, Yu Tao and Yingshi Song, 2017 [7]). However, this method can only measure the internal evaluation of the decision-making unit under the existing technical level, and cannot compare with the cities outside the decision-making unit. The 
third method is a comprehensive evaluation method, which evaluates urban development by establishing an indicator system (Sun et al., 2017), which can systematically reflect the characteristics of the evaluation object and is widely used in economics and society according to the needs of the research [7]. For example, Tan et al. (2016) used this method to analyze the transformation and upgrading of cities [8]. Zhang et al. (2016) analyzed the sustainable development capabilities of cities [9]. In fact, the transformation and upgrading of resource-recycling cities is not a simple economic development, but a leap-forward development caused by technological progress and institutional changes. Its core is to promote economic transformation, social progress and improvement of resources and environment. Therefore, urban development should be reflected in many aspects and evaluated. Therefore, this paper chooses the last method to establish a comprehensive index system, using the latest entropy weight (TOPSOS method) (Technique for Order Preference by Similarity to an Ideal Solution), reasonably set the index weight, consider the time The impact of factors on the ability of economic transformation, the annual economic transformation capacity of 11 resource-recycling cities in 2013-2016, and the analysis of the convergence of economic transformation capabilities of 11 cities during this period.

The rest of the paper is as follows: the second section builds the index system for evaluating the economic transformation ability of resource-recycling cities; the third section introduces the construction of the entropy weight method and the data description; the fourth section conducts empirical analysis; the fifth section presents conclusions and recommendations.

\section{Evaluation Index System of Economic Transformation Capability of Resource Recycling City}

According to the theory of urban economics, the urban economic structure is an economic system consisting of space economy, industrial economy, regional economy and environmental economy. The fundamental purpose of economic transformation is to achieve sustainable urban development, involving economic, social, and transformation processes. Therefore, in the evaluation of the economic transformation capacity of resource-recycling cities, it is necessary to comprehensively consider the three systems of economy, society and environment. The index system of this paper draws on the main indicators of sustainable development of resource-based cities in the "Planning", the "Green Development Index System" and the economic transformation evaluation index system constructed by scholars in the past (Robert and Todd, 2002 [10]; Wu Guanxi et al., 2007 [11]; Georges A. Tanguay, Juste Rajaonson, Jean-Francois Lefebvre, and Lanoie, 2010 [12]; Pang Zhiqiang and Wang Bida, 2012 [13]; Du Dong and Pang Jinxin, 2013 [14]; Wei Chen, Yue Shen and Yanan Wang 2018 [15]) propose an evaluation index system for resource-recycling urban economic transformation capabilities (Table 1). 
Table 1. Evaluation index system of economic transformation capability of resource recycling city.

\begin{tabular}{|c|c|c|c|c|c|}
\hline Primary indicator & Secondary indicators & Three-level indicator & Four-level indicator & unit & $\begin{array}{l}\text { Indication } \\
\text { feature }\end{array}$ \\
\hline \multirow{17}{*}{$\begin{array}{l}\text { The ability of } \\
\text { resource-regeneration } \\
\text { urban economic } \\
\text { transformation }\end{array}$} & \multirow{12}{*}{ Economic adjustment } & \multirow{5}{*}{$\begin{array}{l}\text { The level of economic } \\
\text { development }\end{array}$} & Per capita GDP $x_{1}$ & yuan & + \\
\hline & & & GDP growth rate $x_{2}$ & $\%$ & + \\
\hline & & & Fiscal revenue growth rate $x_{3}$ & $\%$ & + \\
\hline & & & $\begin{array}{l}\text { Manufacturing fixed asset investment } \\
\text { growth rate } X_{4}\end{array}$ & $\%$ & + \\
\hline & & & $\begin{array}{l}\text { Mining industry fixed asset investment } \\
\text { growth rate } x_{5}\end{array}$ & $\%$ & - \\
\hline & & \multirow{3}{*}{$\begin{array}{l}\text { Economic } \\
\text { structure }\end{array}$} & Proportion of total industrial output $x_{6}$ & $\%$ & - \\
\hline & & & $\begin{array}{l}\text { The proportion of added value of the } \\
\text { tertiary industry } x_{7}\end{array}$ & $\%$ & + \\
\hline & & & $\begin{array}{l}\text { Total import and export volume as a } \\
\text { percentage of GDP } x_{8}\end{array}$ & $\%$ & + \\
\hline & & & Financial self-sufficiency rate $x_{9}$ & $\%$ & + \\
\hline & & Economic & Energy consumption per unit gdp $x_{10}$ & $\begin{array}{l}\text { Tons of standard } \\
\text { coal } / 10,000 \text { yuan }\end{array}$ & - \\
\hline & & development capability & Third industry employees ratio $x_{11}$ & $\%$ & + \\
\hline & & & $\begin{array}{l}\text { R\&D expenditure as a percentage of total } \\
\text { output } x_{12}\end{array}$ & $\%$ & + \\
\hline & \multirow{2}{*}{ Social progress } & \multirow{2}{*}{ Quality of Life } & $\begin{array}{l}\text { Per capita disposable income of urban } \\
\text { residents and } x_{13}\end{array}$ & yuan & + \\
\hline & & & $\begin{array}{l}\text { Per capita disposable income of rural } \\
\text { residents } X_{14}\end{array}$ & yuan & + \\
\hline & \multirow{3}{*}{$\begin{array}{l}\text { Environmental } \\
\text { improvement }\end{array}$} & $\begin{array}{l}\text { Social development } \\
\text { ability }\end{array}$ & $\begin{array}{l}\text { The ratio of science education and } \\
\text { cultural health expenditure to public } \\
\text { expenditure in the local total budget } X_{15}\end{array}$ & $\%$ & + \\
\hline & & $\begin{array}{l}\text { Pollution treatment } \\
\text { capacity }\end{array}$ & $\begin{array}{l}\text { Comprehensive utilization of industrial } \\
\text { solid waste } x_{16}\end{array}$ & $\%$ & + \\
\hline & & Pollution discharge & Total industrial exhaust emissions $X_{17}$ & $\begin{array}{l}\text { Billion standard } \\
\text { cubic meters }\end{array}$ & - \\
\hline
\end{tabular}

The economic adjustment has three sub-indicators, including the level of economic development, economic structure and economic development capabilities. The assessment of economic development level includes $X_{1}-X_{4}$, which reflects the impact of factors such as urban economic aggregates and industrial development on the economic level and economic growth rate that should be achieved in economic transformation and upgrading. The economic structure assessment indicators include $x_{5}-x_{9}$, reflecting the changes in industrial structure and internal structure during the economic transformation and upgrading of resource-recycling cities. The industrial structure adjustment of resourcebased and non-resource-based industries and the dependence of regional foreign trade are considered. The economic development assessment includes $X_{10}-X_{12}$, reflecting the health level and sustainability of economic development, and the 
development of resource-based cities after economic transformation and upgrading. It considers the balance of public finances, energy consumption capacity, and the development of the economic sector of the tertiary industry and potential and innovative input capabilities.

Social progress indicators include two secondary indicators of quality of life and social development capabilities. The quality of life assessment includes $X_{13}$ $x_{14}$, reflecting the changes in the living standards of urban and rural residents during the economic transformation of resource-recycling cities. The indicators of social development ability reflect the level of social development capacity, and the use of science education and cultural health expenditures is reflected in the proportion of public expenditure in the local total budget.

Environmental improvement indicators include two sub-indicators of pollution control capacity and pollution discharge. The pollution treatment capacity indicator takes into account the comprehensive utilization capacity of urban industrial solid waste, and the pollution discharge degree indicator represents the change of pollution discharge during the economic transformation and upgrading of resource-recycling cities.

\section{Model Construction and Data Description Based on Entropy Weight Test}

The TOPSIS method is one of the first multi-criteria decision making methods (MCDM) proposed by Hwang and Yoon. The optimal solution for TOPSIS selection is the one that is the shortest positive solution and the farthest to the negative ideal solution (Sevastjanov and Tikhonenko, 2016 [16]; Dace and Blumberga, 2016 [17]). It evaluates and decides on the solution. Its advantages include no requirement for observation sample size, no requirement for data independence, and easy to understand results. Therefore, TOPSIS method is widely used in many fields (Ziemele, Pakere, and Blumberga, 2016 [18]), however, the disadvantage is that the traditional TOPSIS method gives the same weight to each indicator and does not truly reflect the importance of each indicator in the evaluation system. Liu, Q., Wang, S., and Zhang, W (2017) proposed an improved entropy-weighted TOPSIS method, which is an objective assignment method, which uses the size of the evaluation index itself to determine the weight [4]. The entropy weight method is mostly used for multi-objective decision-making and In terms of comprehensive evaluation, its decision-making precision is closely related to its decision-making information. According to the definition of entropy, it is used to measure the degree of uncertainty of things. The smaller the entropy value, the larger the amount of information and the smaller the uncertainty. The degree of order is higher; vice versa.

\subsection{Construction of Entropy Weight Motif Model}

The method of establishing the entropy weight method is: firstly, the original index data is normalized according to the positive and negative index systems to 
obtain the standard index matrix, and then the information entropy value of the index is calculated to determine the corresponding weight, and then the positive and negative are determined. The ideal solution and the Euclidean distance between them, from which the relative closeness of each city to the best state is obtained, and then the ranking of each city is measured. The specific method is as follows.

The first step is to set the initial matrix of evaluation indicators:

$$
X=\left[\begin{array}{cccc}
x_{11} & x_{12} & \cdots & x_{1 n} \\
x_{21} & x_{22} & \cdots & x_{2 n} \\
\vdots & \vdots & \ddots & \vdots \\
x_{m 1} & x_{m 2} & \cdots & x_{m n}
\end{array}\right]
$$

where $m$ is the number of resource-recycling cities and $\mathrm{n}$ is the number of evaluation indicators. Since the units of each indicator are different, the second step needs to normalize each indicator through the extreme method of the forward indicator and the negative indicator. The formula is as follows:

$$
\begin{gathered}
a_{i j}^{+}=\frac{\left[x_{i j}-\min \left(x_{i j}\right)\right]}{\left[\max \left(x_{i j}\right)-\min \left(x_{i j}\right)\right]},\left(\begin{array}{l}
i=1,2, \cdots, n \\
j=1,2, \cdots, m
\end{array}\right) \\
a_{i j}^{-}=\frac{\left[\max \left(x_{i j}\right)-x_{i j}\right]}{\left[\max \left(x_{i j}\right)-\min \left(x_{i j}\right)\right]},\left(\begin{array}{l}
i=1,2, \cdots, n \\
j=1,2, \cdots, m
\end{array}\right)
\end{gathered}
$$

Among them, in the formula The value after standardization for the $i$-th indicator of $j$ city, For the initial value of the $i$-th indicator of $j$ city, The minimum value of the $i$-th indicator in all cities, The maximum value of the $i$-th indicator in all cities. In the evaluation system, four indicators are standardized using negative indicators, and the remaining 13 indicators are standardized using positive indicators.

The third step is to calculate the proportion of the $i$-th indicator of $j$ city. The calculation formula is as follows:

$$
P_{i j}=\frac{a_{i j}}{\sum_{i=1}^{n} a_{i j}}\left(\begin{array}{l}
i=1,2, \cdots n \\
j=1,2, \cdots m
\end{array}\right)
$$

The fourth step is to calculate the information entropy value of each indicator., the formula is:

$$
E_{i j}=-\frac{1}{\ln m} \cdot \sum_{j=1}^{m} P_{i j} \cdot \ln P_{i j}
$$

Then the fifth step is to calculate the information utility value of the indicator. $D_{i j}$, the formula is:

$$
D_{i j}=1-E_{i j}
$$

The sixth step is to calculate the weight of the evaluation index., the formula is: 


$$
W_{i j}=\frac{D_{i j}}{\sum_{j=1}^{m} D_{i j}}
$$

The seventh step is to set the positive and negative ideal solutions. The maximum value of the standardized $i$-index of $j$ city multiplied by the corresponding index weight is the positive ideal solution, and the minimum value is the negative ideal solution:

$$
\begin{aligned}
& A_{i j}=W_{i j} \cdot a_{i j} \\
& A_{j}^{+}=\max \left(A_{i j}\right), A_{j}^{-}=\min \left(A_{i j}\right)
\end{aligned}
$$

Get positive ideal solution set $A^{+}=A\left({ }_{1}^{+}, A_{2}^{+}, \cdots, A_{n}^{+}\right)$. Negative ideal solution set $A^{-}=A\left({ }_{1}^{-}, A_{2}^{-}, \cdots, A_{n}^{-}\right)$. Then calculate the Euclidean distance between each indicator and the positive and negative ideal solutions:

$$
D_{j}^{+}=\sqrt{\sum_{i=1}^{n}\left(A_{i j}-A_{j}^{+}\right)^{2}}, D_{j}^{-}=\sqrt{\sum_{i=1}^{n}\left(A_{i j}-A_{j}^{-}\right)^{2}}, j=1,2, \cdots, m
$$

Finally, calculate the relative closeness of each city and the relative ideal solution:

$$
C_{j}=\frac{D_{j}^{-}}{D_{j}^{+}+D_{j}^{-}}
$$

In formula (9), Between $(0,1)$, the relative closeness value is larger, indicating that the closer the city $\mathrm{j}$ is to the ideal solution, that is, the closer the $C$ value is to 1 , indicating that the index value of the city evaluation is closer to the maximum value of each index. It means that the economic transformation of the city is better; on the contrary, it is reversed. Then, according to the relative closeness, the economic transformation effects of each city are ranked and evaluated.

\subsection{Data Selection and Description}

According to the evaluation index system of resource-recycling urban economic transformation effect constructed in the second part, combined with the classification of resource-recycling cities in the "Planning", the study of prefecture-level administrative districts and considering the availability of data, 11 prefecture-level cities outside the city, Xuzhou City, Suqian City, Aba Tibetan and Qiang Autonomous Prefecture, and Lijiang City were selected as research objects. We compiled the index data of 16 resource-recycling cities from 2001 to 2016. Because some of the indicators in 6 cities including Tonghua City, Xuzhou City and Suqian City were seriously missing, the samples were deleted; according to the data of the remaining 11 cities. According to the time span determined by the "Planning", the data of 2013-2016 was selected for measurement and analysis. Using the entropy weight tom method to measure 2013-2016. The economic transformation effects of the cities, and horizontal comparison and analysis of the changes in the economic transformation effect of the cities during this period. The data in this paper are from the China Statistical Yearbook from 2013 
to 2016, the Statistical Yearbook of the provinces to which the municipalities belong, and the Statistical Communiqué of National Economic and Social Development of each city. The missing data is based on the previous research methods. The existing data is interpolated using mean interpolation.

\section{An Empirical Analysis of the Economic Transformation Capability of Resource Regeneration Cities}

The weights, positive and negative ideal solutions of each evaluation index of economic transformation of resource-recycling cities and the Euclidean distance to positive and negative ideal solutions are obtained by entropy-weighted tend an model construction method. The relative closeness of the city and the relatively ideal solution. The results are shown in Table 2. The results show that 11 cities show three types of changes. The rankings of Tangshan City, Linyi City, Anshan City, Panjin City and Huludao City are gradually rising. The rankings of Zibo City, Maanshan City, Luoyang City and Baotou City are From the front to the last; the rankings of Nanyang City and Zhangye City are full of twists and turns. The combined average increased from 0.419 in 2013 to 0.455 in 2016, an increase of $8.6 \%$. Among them, the value of $c$ in Tangshan City, Linyi City, Anshan City, Panjin City and Huludao City has risen rapidly, and its ranking has become more and more advanced. In the long run, these five cities have a growing trend and are relatively stable; In terms of ownership, the three cities of Anshan City, Panjin City and Huludao City belong to Liaoning Province. After the "falling cliff fall" in Liaoning Province in 2014, they have to adopt economic transformation as soon as possible, promote development momentum with reform and innovation, and promote Industrial structure and economic restructuring,

Table 2. Comprehensive evaluation of the comprehensive effects of economic transformation in various cities from 2013 to 2016.

\begin{tabular}{ccccccccc}
\hline \multirow{2}{*}{ City } & \multicolumn{2}{c}{ year 2013} & \multicolumn{2}{c}{ Year 2014} & \multicolumn{2}{c}{2015} & \multicolumn{2}{c}{2016} \\
\cline { 2 - 8 } & $c$ value & Sort & c value & Sort & c value & Sort & c value & Sort \\
\hline Tangshan City & 0.315 & 9 & 0.445 & 3 & 0.425 & 5 & 0.483 & 4 \\
Zibo City & 0.690 & 1 & 0.402 & 6 & 0.333 & 7 & 0.429 & 8 \\
Linyi City & 0.253 & 10 & 0.344 & 9 & 0.305 & 8 & 0.497 & 2 \\
Maanshan City & 0.645 & 2 & 0.376 & 8 & 0.291 & 11 & 0.450 & 6 \\
Anshan City & 0.434 & 4 & 0.411 & 5 & 0.490 & 3 & 0.525 & 1 \\
Panjin City & 0.340 & 7 & 0.496 & 1 & 0.515 & 2 & 0.455 & 5 \\
Huludao City & 0.198 & 11 & 0.473 & 2 & 0.589 & 1 & 0.490 & 3 \\
Luoyang City & 0.423 & 5 & 0.287 & 11 & 0.297 & 10 & 0.412 & 10 \\
Nanyang City & 0.398 & 6 & 0.319 & 10 & 0.343 & 6 & 0.414 & 9 \\
Baotou City & 0.588 & 3 & 0.392 & 7 & 0.301 & 9 & 0.408 & 11 \\
Zhangye City & 0.330 & 8 & 0.425 & 4 & 0.453 & 4 & 0.444 & 7 \\
Mean & 0.419 & & 0.397 & & 0.395 & & 0.455 & \\
\hline
\end{tabular}


improving the quality and efficiency of development, and striving to ensure and improve people's livelihood and promote the development strategy of various social undertakings (Gao Yang, 2014 [19]; Sun Shujun, 2018 [20]). Tangshan City once had abundant resources such as coal and iron ore. The major industries used to include: chemical, coal, smelting, steel and other industries. After the introduction of the "Regulations" in 2013, as these industries are resourcedependent and environmentally disruptive industries, some industries have gradually withdrawn from the market, while others have continued to take the status of urban leading industries through transformation and upgrading, such as the coal chemical recycling industry. Steel manufacturing, equipment manufacturing and other industries. However, Tangshan City has also developed some new industries in recent years, such as logistics, new energy, new materials and bio-pharmaceutical industries. The coexistence of such new industries with traditional industries is the reason why the economic transformation effect has not achieved a leading position.

Zibo City, Maanshan City, Luoyang City and Baotou City respectively fell from a higher ranking in 2013 to a lower position. Zibo City is an important heavy industrial city and an old industrial base in China. Although the proportion of service industry in the whole city has gradually increased in recent years, the increase rate is not large and is lower than the national and provincial average. It shows that the structural characteristics of industrialized industries formed by Zibo City relying on resources are still very obvious. In the inter-industry structure, the service industry's ability to support the industry is insufficient, and the industry cannot be further transformed and developed; the proportion of light and heavy industry in the industry's total output value remains wide, and the proportion of heavy industry continues to remain above $80 \%$. As can be seen from Table 3. In terms of secondary indicators, Zibo City

Table 3. Evaluation results of secondary indicators for economic transformation effect of resource-recycling cities.

\begin{tabular}{|c|c|c|c|c|c|c|c|c|c|c|c|c|}
\hline \multirow{2}{*}{ City } & \multicolumn{4}{|c|}{ Economic adjustment } & \multicolumn{4}{|c|}{ social progress } & \multicolumn{4}{|c|}{ Environmental improvement } \\
\hline & 13 & 14 & 15 & 16 & 13 & 14 & 15 & 16 & 13 & 14 & 15 & 16 \\
\hline Tangshan City & 0.21 & 0.37 & 0.40 & 0.43 & 0.35 & 0.33 & 0.63 & 0.43 & 0.34 & 0.62 & 0.42 & 0.84 \\
\hline Zibo City & 0.25 & 0.38 & 0.37 & 0.42 & 0.69 & 0.78 & 0.71 & 0.69 & 0.91 & 0.27 & 0.18 & 0.24 \\
\hline Linyi City & 0.41 & 0.36 & 0.34 & 0.48 & 0.41 & 0.30 & 0.35 & 0.35 & 0.15 & 0.33 & 0.24 & 0.70 \\
\hline Maanshan & 0.40 & 0.35 & 0.33 & 0.37 & 0.40 & 0.44 & 0.59 & 0.70 & 0.80 & 0.40 & 0.10 & 0.53 \\
\hline Anshan City & 0.38 & 0.43 & 0.43 & 0.53 & 0.52 & 0.21 & 0.34 & 0.28 & 0.44 & 0.43 & 0.59 & 0.64 \\
\hline Panjin City & 0.33 & 0.45 & 0.42 & 0.42 & 0.59 & 0.33 & 0.42 & 0.36 & 0.30 & 0.72 & 0.70 & 0.70 \\
\hline Huludao & 0.35 & 0.46 & 0.43 & 0.46 & 0.20 & 0.22 & 0.29 & 0.16 & 0.10 & 0.56 & 0.92 & 0.95 \\
\hline Luoyang City & 0.38 & 0.37 & 0.44 & 0.49 & 0.15 & 0.21 & 0.13 & 0.12 & 0.46 & 0.00 & 0.05 & 0.24 \\
\hline Nanyang City & 0.41 & 0.34 & 0.46 & 0.47 & 0.17 & 0.25 & 0.14 & 0.14 & 0.42 & 0.28 & 0.21 & 0.36 \\
\hline Baotou City & 0.39 & 0.44 & 0.41 & 0.45 & 0.38 & 0.47 & 0.46 & 0.46 & 0.71 & 0.18 & 0.00 & 0.13 \\
\hline Zhangye City & 0.45 & 0.46 & 0.48 & 0.49 & 0.12 & 0.10 & 0.04 & 0.15 & 0.28 & 0.41 & 0.48 & 0.42 \\
\hline
\end{tabular}


has maintained its first and second positions in the indicator of social progress, and has been in a relatively backward position in terms of economic adjustment, especially on environmental improvement indicators.

From the first place to the last place, it can be seen that Zibo City's efforts to change its economic structure in recent years are still insufficient. Relying on traditional heavy industry not only affects its economic development potential and economic restructuring, but also brings social problems such as environmental pollution and waste of resources. Further, the problem of a decline in the ranking of economic transformation capability has arisen. The situation in Maanshan City and Baotou City is similar to that of Zibo City, which is a decline in the value of economic adjustment. This shows that in recent years, with the rapid development of industrialization and urbanization, these cities have continuously optimized the economic structure to promote urban economic transformation and upgrading. However, the structural contradictions in the economy have not yet been fundamentally resolved. In addition, the adjustment of the industrial structure of the manufacturing and service industries is relatively slow, and the proportion of high-tech industries is also very low. All these reasons have led to problems in the economic adjustment of the cities, and even declined. From the indicator of social progress, Maanshan City and Baotou City have seen significant improvement, among which Maanshan City has achieved a successful transformation in social progress indicators (from 0.4 in 2013 to 0.7 in 2016). From the indicator of environmental improvement, these four cities fell from the top four to the end. The above shows that the economic adjustment of these cities is slow, although the social progress is remarkable, but this remarkable is based on industries that still rely on resource-based industries, such as chemical, metallurgy, ceramics, building materials, etc., which have great pollution to the environment, and the stagnation of economic adjustment. The deterioration of environmental improvement is the cause of the decline in the comprehensive ranking of Zibo City, Maanshan City, Luoyang City and Baotou City.

From Table 2, it can also be seen that the difference in $\mathrm{C}$ values among cities in 20113 is large, with cities significantly lower than the average value of 0.419 , indicating that there is a large gap in economic transformation capacity among 11 cities. By 2016, the difference in C values among cities is gradually narrowing, and the gap is significantly smaller than that in 2013. As can be seen from Figure 1 , the average annual $\mathrm{c}$ value and change rate of 11 cities are different. Huludao city has a growth rate of $148.2 \%$ from 2013 to 2015, while zibo city, ma' anshan city, Luoyang city and Baotou city have negative growth rates. Based on the above analysis, it is found that the reason why the city with lower original value has developed into a higher city and the city with higher value has changed into a city with lower original value is that the index of environmental improvement has changed significantly, and this change is due to the optimization of industrial structure and the formulation of effective environmental improvement measures, which play an important role in the improvement of urban environment in 


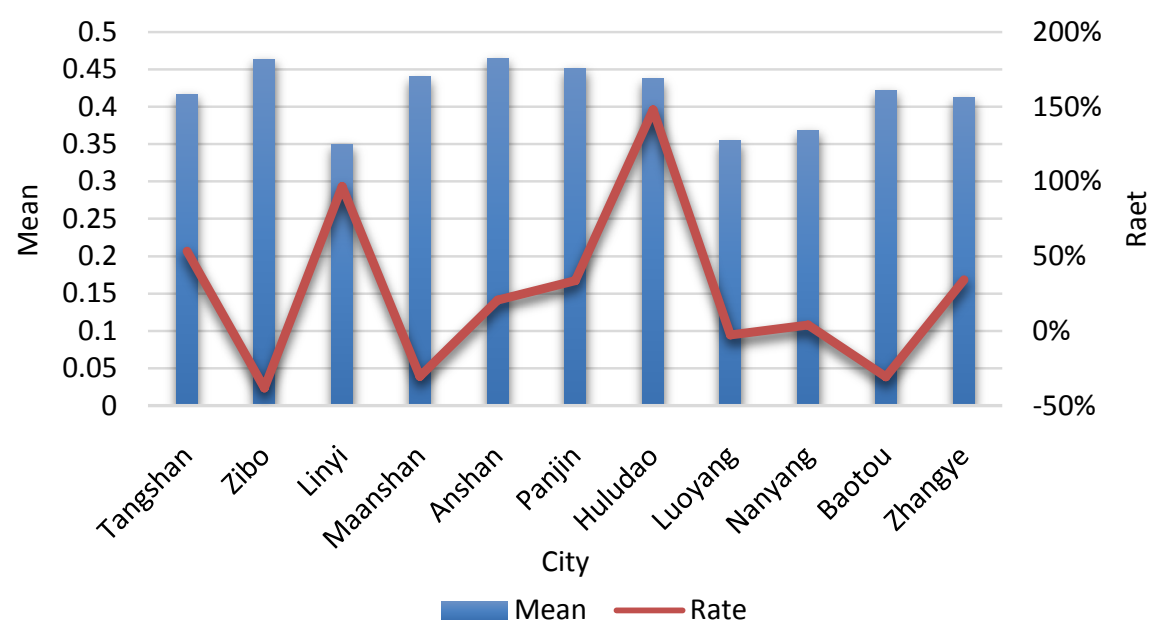

Figure 1. 11 city comprehensive relative closeness mean and rate of change.

the process of economic transformation, so economic adjustment has become the key index to measure the economic transformation capability.

\section{Convergence Analysis}

The above analysis finds that the order of economic transformation capability between cities and the narrowing of the $C$-value gap between cities, in order to further analyze the reasons for this situation and to propose more ways to promote economic transformation, the need for economic transformation capacity convergence Carry out inspection. According to the method of testing convergence proposed by previous scholars, the main commonly used are: $\sigma$ convergence, $\beta$ convergence and club convergence. In view of the collected data and the economic gap between cities, this paper will conduct a beta convergence test.

The $\beta$ convergence is divided into absolute $\beta$ convergence and conditional $\beta$ convergence. Absolute beta convergence reflects the convergence characteristics of the growth rate of the economically transforming city's economic transformation capability (ie, relative closeness), which refers to the city with a lower initial growth rate than the city with a higher growth rate of economic transformation capability. Faster, that is, there is a negative correlation between the growth rate of economic transformation capability and the ability of economic transformation at the beginning of the period, and the lower cities have a tendency to catch up with higher cities. The model is:

$$
\ln \left(\frac{c_{j, t+1}}{c_{j i, t}}\right)=\alpha+\beta \ln c_{j, t}+\varepsilon_{j, t}
$$

Among them, $c_{j, t}$ Express $j$ city $t$ Economic transformation capacity, $c_{j, t+1}$ Express $\mathrm{j}$ city $t+1$ Economic transformation capability, $\left(c_{j, t+1} / c_{j, t}\right)$ indicating the growth rate of economic transformation capability, $\alpha$ is a constant term, $\beta$ is $t$ The coefficient of economic transformation capability, $\varepsilon_{j, t}$ It is a random error term. If $\beta$ is negative and passes the significance level test, indicating that ci- 
ties with lower economic transformation capacity have greater growth rates and "catch-up effects" for regions with higher capacity, the city's economic transformation capability shows absolute convergence. situation.

The conditional $\beta$ convergence is that after adding other influencing factors, the cities with lower economic transformation ability are still growing at a relatively high rate, that is, there is a negative correlation between the relative closeness growth rate and the relative closeness of each city. If $\beta$ is positive, it means that the cities that started to fall behind have no "catch-up effect", and the gap between them and the higher-ranking cities is getting bigger and bigger, which leads to the economic transformation ability of each city cannot converge to their respective stable levels, showing a divergent situation. Since the conditional $\beta$ convergence incorporates regional factors, that is, the development conditions of each city are different, it is impossible to converge to the same level, and the result is more realistic. The model is as follows:

$$
\ln \left(\frac{c_{j, t+1}}{c_{j, t}}\right)=\alpha+\beta \ln c_{j, t}+\sum_{i}^{n} \gamma_{i} Z_{i, j, t}+\varepsilon_{j, t}
$$

Among them, the other items are the same as formula (10). Express The coefficients of the control variables, Express The first city of the th city Control variables. With regard to the selection of control variables, we draw on the evaluation index system of economic transformation effects of resource-recycling cities, and use the secondary indicators of economic adjustment to reflect the economic transformation ability of a city. The indicator of the growth rate of fiscal revenue to reflect the level of economic development is because a city's fiscal revenue depends on the city's industry. Due to the bottleneck of resourcebased urban economic growth, it will appear when the city is over-reliant on a specific resource. Diminishing marginal returns and resource bottlenecks, the so-called "resource curse." Therefore, the growth rate of fiscal revenue can well reflect the economic activities of a city's industry; the proportion of the added value of the tertiary industry and the ratio of total import and export to GDP are used to reflect the economic structure. This is because of the added value of the tertiary industry. The ratio can reflect the true situation of the three industries in the city. According to the "comparative advantage theory", a city will export its comparatively advantageous goods, import its relatively inferior goods, and the relative advantages of resource-recycling cities in the transition period. The industry is still a traditional resource-based industry, so the proportion of imports and exports will reflect the industrial structure of the city; according to previous scholars' research, most of the energy consumption per unit of gdp is used to reflect the economic development capability.

Finally, the absolute conditional convergence model and the relative conditional convergence model are determined by the Hausman test as the fixed effect model, and there is no correlation and multicollinearity between the variables. The regression results are shown in Table 4 . It can be seen from Table 4 that the F statistics of both models have passed the $1 \%$ significance test, indicating that 
Table 4. Results of $\beta$ convergence analysis of economic transformation capability of resource recycling cities.

\begin{tabular}{ccc}
\hline variable & $\begin{array}{c}\text { Absolute conditional } \\
\text { convergence model }\end{array}$ & $\begin{array}{c}\text { Relative condition } \\
\text { convergence model }\end{array}$ \\
\hline $\ln c$ & $-1.014^{* * *}$ & $-0.951^{* * *}$ \\
$(-9.06)$ & $(-10.54)$ \\
$g$ & & $0.277^{* * *}$ \\
service & & $13.40)$ \\
trade & & $1.522^{*}$ \\
energy & & $-2.232^{*}$ \\
Cons & & $(-2.03)$ \\
$R^{2}$ & $-0.909^{* * *}$ & -0.104 \\
Adj $R^{2}$ & $(-8.33)$ & $(-1.32)$ \\
F-statistic & 0.769 & $-1.163^{* *}$ \\
& 0.689 & $(-2.70)$ \\
& $82^{* * *}$ & 0.916 \\
\end{tabular}

Note: 1$)^{* * *}, * *, *$ respectively indicate significant at the level of $\left.1 \%, 5 \%, 10 \% ; 2\right) t$-statistics corresponding to each parameter in parentheses; 3 ) $g$ is fiscal revenue Growth rate, service is the proportion of value added in the tertiary industry, trade is the proportion of total imports and exports, and energy is the energy consumption per unit of GDP.

the model selection is appropriate and can accurately reflect the relationship between the growth rate of economic transformation capability and the ability of economic transformation at the beginning of the period. The absolute conditional convergence model and the relative conditional convergence model have $\beta$ of -1.014 and -0.951 , respectively, and both pass the $1 \%$ significance test, indicating that after adding the factors affecting economic transformation ability, there is still a "catch-up effect" of backward areas. That is, the gap in the economic transformation capacity of these 11 resource-recycling cities is gradually narrowing. However, from the point of convergence speed, the convergence rate of the absolute conditional convergence model is significantly faster than the relative condition convergence rate. The difference between the two models indicates that the short-term convergence gap still exists between cities due to different economic development differences.

As far as the impact of control variables on the growth rate of economic transformation capacity is concerned: 1) The fiscal revenue growth rate coefficient has passed the $1 \%$ significance test and is significantly non-zero, meaning that every one percent increase in fiscal revenue growth rate will result in The growth rate of economic transformation capacity has increased by 0.277 percentage points. This is because the traditional industrial development of resource-based cities has been very mature in the past. According to the production theory, there will be marginal returns and resource bottlenecks, so the growth rate of urban fiscal revenue will not change significantly. However, when 
the city turned to other emerging industries, these new industries generally have high added value, high returns, and economies of scale. Increasing output leads to an increase in government revenues and an increase in fiscal revenue growth. 2) The value-added ratio of the added value of the tertiary industry passed the $10 \%$ significance test and was significantly zero, which showed a positive correlation with the growth rate of economic transformation capability, that is, the proportion of the added value of the tertiary industry. The increase in the convergence of economic transformation ability has a significant role in promoting, indicating that economic restructuring is conducive to the reduction of economic transformation capacity; 3) The ratio of the total export value has passed the $10 \%$ significance test and is significantly less than 0 , showing a negative correlation with the growth rate of economic transformation capacity. That is, the increase in the proportion of total import and export has a significant hindrance to the convergence of economic transformation capability. It shows that in the short term, the economic adjustment method of using a large number of exports of traditional industrial commodities and importing relatively inferior commodities is not conducive to the narrowing of the difference in economic transformation capability; 4) The unit gdp energy consumption coefficient has not passed the significant test, and the energy consumption is reflected here. The ability of economic development is not the main reason that affects the convergence of economic transformation capability. The reason for the insignificance may be due to the small sample capacity.

\section{Conclusions and Suggestion}

This paper establishes a comprehensive evaluation index system of resource-recycling urban economic transformation ability from three aspects of economic adjustment, social progress and environmental improvement. Through the entropy rights TOPSIS method, the economic transformation ability of 11 resource-recycling cities in China has been carried out in 2013-2016. On the basis of this, the $\beta$ convergence is used to empirically analyze the convergence of the economic transformation ability of resource-recycling cities with its influencing factors. The conclusions are as follows: 1) There are three kinds of changes in the 11 cities, that is, from the low order to the high (Tangshan, Linyi, and Liaoning), and the rankings fall from high to low (Zibo, Maanshan, Luoyang, Baotou). There is also little change in the city order (Nanyang, Zhangye City). The large changes in the order of these cities reflect that the economic transformation of each city is different. Cities with better economic restructuring will increase the ranking, while cities with insufficient transformation will be overtaken by the latter and fall to the low level; 2) The gap in economic transformation between the 11 cities in 2013 is large, but as time goes by, the gap between cities is gradually narrowing and the reduction is very obvious; 3) Economic adjustment becomes a key indicator for determining the ability of economic transformation; 4) The economic transformation ability of resource-recycling cities has absolute $\beta$ conver- 
gence and conditional $\beta$ convergence, indicating that China's resource-recycling cities will automatically develop to their respective stable states, that is, the gap between the economic transformation capabilities of 11 cities will become more and more Small, thus achieving the "catch-up effect" of backward regions on developed regions. From the point of view of convergence speed, the convergence rate of the absolute conditional convergence model is significantly faster than the relative condition convergence speed, that is, the short-term convergence gap still exists between cities due to different economic development differences.

The economic transformation ability of each city has absolute $\beta$ convergence and conditional $\beta$ convergence. The convergence verification will lay a good theoretical foundation and realistic basis for economic transformation capability assessment and policy formulation. Based on the conclusions, the policy recommendations are as follows: Optimize the industrial structure, the municipal governments should improve the economic structure adjustment, and gradually realize the industrial upgrading and transformation. It is precisely because of the stagnation of the economic structure that the ranking is declining. In the $\beta$ convergence analysis, the fiscal revenue growth rate and the third The proportion of industrial added value has a significant positive correlation with the growth rate of economic transformation capacity, indicating that the economic structure changes reflected behind it are the impact of the growth rate of economic transformation capacity. The proportion of import and export has a significant negative correlation with the growth rate of economic transformation capability, indicating that the development model of continuing to export current comparative advantage goods and importing relatively inferior commodities will hinder the growth of economic transformation capability. The enlightenment to other resource-based cities is that the upgrading and transformation of resource-based industries is based on the original development path that is gradually replaced by resource-based industries, and fails to complete the goal of resource-based urban transformation. Therefore, after the resource industry transformation realizes the initial substitution of the original development path, resource-based cities should steadily pursue the search and development of resource-substituting industries, further optimize the economic structure, improve the quality of economic development and the level of scientific and technological innovation, and foster development strategies. Sexual emerging industries, accelerate the development of modern service industries, and strive to complete the requirements of economic transformation within the planning period.

\section{Conflicts of Interest}

The author declares no conflicts of interest regarding the publication of this paper.

\section{References}

[1] Li, J. and Tang, Z. (2017) Research on the Structural Growth of Recycling Re- 
source-Based City Industry-Taking Tangshan City as an Example. Geography Research, 36, 707-718.

[2] Li, B. and Dewan, H. (2017) Efficiency Differences among China's Resource-Based Cities and Their Determinants. Resources Policy, 51, 31-38.

https://doi.org/10.1016/j.resourpol.2016.11.003

[3] Li, H., Long, R. and Chen, H. (2013) Economic Transition Policies in Chinese Resource-Based Cities: An Overview of Government Efforts. Energy Policy, 55, 251-260. https://doi.org/10.1016/j.enpol.2012.12.007

[4] Liu, Q.Q., Wang, S.J. and Zhang, W.Z. (2017) China's Municipal Public Infrastructure: Estimating Construction Levels and Investment Efficiency Using the Entropy Method and a DEA Model. Habitat International, 64, 59-70.

https://doi.org/10.1016/j.habitatint.2017.04.010

[5] Zhang, W., Zhao, F. and Wang, Y.T. (2016) An Evaluation of the Comprehensive Development Capacity_Energy-Based Cities in China. Energy Procedia, 104, 509-514. https://doi.org/10.1016/j.egypro.2016.12.086

[6] Haghshenas, H., Vaziri, M. and Gholamialam, A. (2015) Evaluation of Sustainable Policy in Urban Transportation Using System Dynamics and World Cities Data: A Case Study in Isfahan. Cities, 45, 104-115.

https://doi.org/10.1016/j.cities.2014.11.003

[7] Sun, X., Liu, X.S., Li, F., Tao, Y. and Song, Y.S. (2017) Comprehensive Evaluation of Different Scale Cities' Sustainable Development for Economy, Society, and Ecological Infrastructure in China. Journal of Cleaner Production, 163, S329-S337. https://doi.org/10.1016/j.jclepro.2015.09.002

[8] Tan, J., Zhang, P., Lo, K., Li, J. and Liu, S. (2016) The Urban Transition Performance of Resource-Based Cities in Northeast China. Sustainability, 8, 1022. https://doi.org/10.3390/su8101022

[9] Zhang, L., Xu, Y., Yeh, C.-H., Liu, Y. and Zhou, D.Q. (2016) City Sustainability Evaluation Using Multi-Criteria Decision Making with Objective Weights of Interdependent Criteria. Journal of Cleaner Production, 131, 491-499. https://doi.org/10.1016/j.jclepro.2016.04.153

[10] Herendeen, R.A. and Wildermuth, T. (2002) Resource-Based Sustainability Indicators: Chase County, Kansas, as Example. Ecological Economics, 42, 243-257. https://doi.org/10.1016/S0921-8009(02)00056-3

[11] Wu, G.X., Liu, Y.Z. and Fu, G.H. (2007) Resource-Based City Transformation Evaluation System under the Concept of Sustainable Development. Resources Development and Market, No. 1, 28-31.

[12] Tanguay, G.A., Rajaonson, J., Lefebvre, J.-F. and Lanoie, P. (2010) Measuring the Sustainability of Cities: An Analysis of the Use of Local Indicators. Ecological Indicators, 10, 407-418. https://doi.org/10.1016/j.ecolind.2009.07.013

[13] Pang, Z.Q. and Wang, B.D. (2012) Research on Economic Transformation Evaluation System in Resource Exhausted Areas. Statistical Research, 29, 73-79.

[14] Du, D. and Pang, J.X. (2013) A Review of China's Urban Economic Transformation Measurement Research. Western Forum, 23, 85-90.

[15] Chen, W., Shen, Y. and Wang, Y.N. (2018) Evaluation of Economic Transformation and Upgrading of Resource-Based Cities in Shaanxi Province Based on an Improved TOPSIS Method. Sustainable Cities and Society, 37, 232-240. https://doi.org/10.1016/j.scs.2017.11.019

[16] Sevastjanov, P. and Tikhonenko, A. (2016) Direct Interval Extension of TOPSIS 
Method. Springer, Berlin Heidelberg.

[17] Dace, E. and Blumberga, D. (2016) How Do 28 European Union Member States Perform in Agricultural Greenhouse Gas Emissions? It Depends on What We Look at: Application of the Multi-Criteria Analysis. Ecological Indicators, 71, 352-358. https://doi.org/10.1016/j.ecolind.2016.07.016

[18] Ziemele, J., Pakere, I. and Blumberga, D. (2016) The Future Competitiveness of the Non-Emissions Trading Scheme District Heating Systems in the Baltic States. Applied Energy, 162, 1579-1585. https://doi.org/10.1016/j.apenergy.2015.05.043

[19] Yang, G. (2014) Ten Advantages of Economic Development in Liaoning Province under the Current Economic Situation. China Market, No. 46, 49-50.

[20] Sun, S.J. (2018) Research on the Relationship between Industrial Structure and Employment Structure in Liaoning Province. Journal of Shenyang University of Technology (Social Science Edition), 11, 57-61. 